\title{
Instruments and Methods
}

\section{Complete determination of ice crystal orientation using Laue X-ray diffraction method}

\author{
Atsushi MIYAMOTO, ${ }^{1}$ Ilka WEIKUSAT, ${ }^{2}$ Takeo $\mathrm{HONDOH}^{1}$ \\ ${ }^{1}$ Institute of Low Temperature Science, Hokkaido University, Sapporo 060-0819, Japan \\ E-mail: miyamoto@lowtem.hokudai.ac.jp \\ ${ }^{2}$ Alfred Wegener Institute for Polar and Marine Research, Columbusstrasse, D-27568 Bremerhaven, Germany
}

\begin{abstract}
Ice crystal orientation fabric data from ice cores contain important information concerning the internal structure and the flow behaviour of ice sheets. When ice cores are recovered from the Antarctic and Greenland ice sheets, crystal orientation measurements are performed immediately to obtain fundamental physical property information. In the past, we have measured the $c$-axis orientation of ice crystals by a manual optical method using a universal stage. This method is very time-consuming, involving tedious work in a cold laboratory. Recently, automated systems have been developed that enable measurement of $c$-axis orientation, grain size and other microstructures. However, in order to detect the full crystal orientation of an ice crystal, we also need information on its a-axis orientation. A variety of other crystal orientation measurement methods have previously been discussed, but some shortcomings for ice-core studies cannot be neglected. We have developed a crystal-orientation analysing device using the Laue X-ray diffraction method. As this device can measure the orientations of all crystal axes with high accuracy, it is possible to obtain new microstructure information on natural ice crystals. For the first time, we are able to quantify very low subgrain misorientation angles in polar icecore samples, allowing us to investigate micro-deformation features of individual crystals. Here we discuss the analysis process, which is customized to measure standard ice thin sections, and show preliminary results.
\end{abstract}

\section{INTRODUCTION}

Ice masses in polar regions show various deformation characteristics depending on stress, temperature, hydrostatic pressure and other parameters (Budd and Jacka, 1989). Deformation of ice in glaciers and ice sheets is controlled mainly by dislocation activity in ice crystals (Schulson and Duval, 2009). Thus, the formation, accumulation and recovery of dislocations determine the strength of the material. Accumulated in subgrain boundaries as arrays, dislocations cause lattice misorientations (Weertman and Weertman, 1992; Hull and Bacon, 2001). Characteristics of the probable dislocation types involved in this misorientation can be determined if full crystal orientation measurements are available (Prior and others, 2002). Since different subgrain boundary types, classified by shape and $c$-axis orientations, have been observed as major microstructure features during creep tests on polar and artificial ice (Hamann and others, 2007; Weikusat, 2009), we can improve our knowledge of dislocation activity using high-accuracy, full crystal orientation analysis on the subgrain scale. To determine microstructural features of natural ice-core samples, the measurement device must be suitable for ice crystals of a few millimetres to several centimetres in diameter.

Three predominant techniques are employed to measure orientation of ice crystals: optical observation, etch-pit observation and electron backscatter diffraction.

The most traditional course is an optical approach using a Rigsby stage, a universal stage with four rotation axes. This method utilizes the birefringence and extinction of the optically uniaxial ice crystal between crossed polarizers (Rigsby, 1951; Langway, 1958; Kamb, 1962). Because a typical ice crystal is hexagonal, with only one optical axis, the only measurable orientation is the $c$-axis. Although this method requires elaborate and time-consuming measurement procedures, it has a major advantage: abundant previous studies are available for data comparison using this method (e.g. Rigsby, 1951; Gow and Williamson, 1976; Herron and Langway, 1982; Azuma and Higashi, 1985; Alley and others, 1995). Thus fabric patterns (e.g. single-maximums or girdles) exhibited by different ice-core samples are comparable even if measurement methods are different.

Automated devices also using the principles of the optical extinction method have become available since the late 1990s (Wang and Azuma, 1999; Wilen and others, 2003; Wilson and others, 2007) and are now commonly used in ice-core studies. The chief merits of these analysers are automation and speed: each thin-section sample takes just a few tens of minutes to process. However, automated techniques have a low angular resolution $\left(\sim 5^{\circ}\right)$, and we know empirically that large artefact errors occur, possibly due to illumination problems (M. Montagnat and others, unpublished information). Furthermore, the measured angles deviate from the true angles due to the large differences between the refractive indices of air and ice if $c$-axes are aligned with high angles with respect to the thin section (Langway, 1958).

The second major method of crystal orientation measurement is by observation, under a microscope, of etch pits, which are generated by the application of a polyvinyl formal solution (Higuchi, 1958; Matsuda, 1979). As the etch pits form shapes of a section cut from a hexagonal column, the full crystal orientation can be determined. This 
Table 1. Comparison of crystal orientation measurement methods for ice samples

\begin{tabular}{|c|c|c|c|c|c|}
\hline Method & Device & Information & Merits & Shortcomings & $\begin{array}{c}\text { Source } \\
\text { (for example) }\end{array}$ \\
\hline $\begin{array}{l}\text { Manual optical } \\
\text { method }\end{array}$ & Universal stage & $c$-axis & $\begin{array}{c}\text { Many comparable datasets } \\
\text { with good statistics }\end{array}$ & $\begin{array}{l}\text { 1. Tedious and } \\
\text { time-consuming work } \\
\text { 2. Low angular resolution }\end{array}$ & Langway (1958) \\
\hline $\begin{array}{l}\text { Automated } \\
\text { optical method }\end{array}$ & $\begin{array}{l}\text { Commercial analyser } \\
\text { or developed their } \\
\text { own equipment }\end{array}$ & $\begin{array}{l}c \text {-axis, } \\
\text { grain size }\end{array}$ & Automated procedure & $\begin{array}{l}\text { 1. Low angular resolution } \\
\text { 2. Artefact error }\end{array}$ & $\begin{array}{c}\text { Wang and Azuma } \\
\text { (1999); Wilson and } \\
\text { others (2007) }\end{array}$ \\
\hline Etch pits & Microscope & $c$ - and a-axes & a-axis is measurable & $\begin{array}{l}\text { 1. Tedious and } \\
\text { time-consuming work } \\
\text { 2. Low angular resolution } \\
\text { 3. Complicated procedure }\end{array}$ & Matsuda (1979) \\
\hline EBSD & $\begin{array}{c}\text { SEM with EBSD and } \\
\text { cold chamber or } \\
\text { stage }\end{array}$ & $\begin{array}{l}\text { Every crystal } \\
\text { orientation with } \\
\text { area mapping }\end{array}$ & $\begin{array}{l}\text { 1. Area mapping of crystal } \\
\text { orientation } \\
\text { 2. High angular resolution } \\
\text { 3. Automated procedure } \\
\text { 4. All crystal axis orientation } \\
\text { is measurable }\end{array}$ & $\begin{array}{l}\text { 1. Small measurement area } \\
\left(\mathrm{a} \text { few } \mathrm{mm}^{2}\right) \\
\text { 2. Cold chamber or stage } \\
\text { is necessary }\end{array}$ & $\begin{array}{c}\text { Iliescu and others } \\
\text { (2004); Obbard and } \\
\text { others (2006) }\end{array}$ \\
\hline $\begin{array}{l}\text { Laue X-ray } \\
\text { method }\end{array}$ & $\begin{array}{c}\text { X-ray source, camera } \\
\text { and pulse motor } \\
\text { stages }\end{array}$ & $\begin{array}{l}\text { Every crystal } \\
\text { orientation at } \\
\text { measured points }\end{array}$ & See text & See text & $\begin{array}{l}\text { Miyamoto and others } \\
\text { (2005); this study }\end{array}$ \\
\hline
\end{tabular}

method also involves laborious, time-consuming work in a cold laboratory. Furthermore, the results depend on the skill of the operator, and only low angle resolutions $\left(>5^{\circ}\right)$ can be obtained. In addition, a reliable method to generate a measurable etch pit on the ice surface is difficult to establish because the density of the polyvinyl formal solution, sublimation time, temperature and other factors strongly influence the quality of etch-pit shape. Additionally, the shape of the etch pits changes every moment (personal communication from N. Azuma, 2010). The advantage of the etch-pit method is that we can measure $c$ - and a-axes orientations with high spatial resolution (several tenths of a micrometre), strongly depending on the visibility of the etch pit and thus the operator's skill.

The third method for crystal orientation measurements is electron backscatter diffraction (EBSD) used as an add-on package with a scanning electron microscope (SEM; Randle and Engler, 2000). This is a long-established method in metallurgy, material science and geology (Humphreys, 2001; Pennock and Drury, 2005) but is rarely used for ice. EBSD enables area mapping of crystal orientation with high spatial resolution, but the measurable area for mapping is normally small (a few $\mathrm{mm}^{2}$ ) due to the small sample size of a few $\mathrm{cm}^{2}$ (Iliescu and others, 2004; Obbard and others, 2006; Piazolo and others, 2008). This small sample size is problematic for the localization of relevant structures since natural polar ice-core samples contain large grains and a heterogeneous distribution of microstructure features. Moreover, an expensive and complex measurement set-up is required to measure ice-core samples, including an SEM equipped with an EBSD detector and cryogenic thermostat chamber or stage. The measurement conditions (e.g. the complicated sublimation and condensation dynamics in a vacuum) must also be controlled (Iliescu and others, 2004; Weikusat and others, in press). Advantages of this method are full automation and the possibility of detecting all crystal axis orientations with high accuracy.

All three methods described above have recently been used in ice-core studies. Currently, the most common technique is the automated optical method because no special skills are required to measure crystal orientation, and advanced commercial devices are available.

X-ray diffraction was used by M. von Laue in 1912-13 to prove the periodic lattice structure of crystals and the electromagnetic character of X-radiation (Ewald, 1962). This method, named after Laue, is now primarily used to measure single crystal orientations and is traditional for crystal orientation measurements; the approach is still common in material sciences. In our study, we adapt this method, for the first time, to polycrystalline samples from an ice sheet. Merits, shortcomings and sources are summarized in Table 1.

\section{EXPERIMENTAL METHODS}

The experimental arrangement for our full crystal orientation fabric analyser is shown in Figure $1 \mathrm{a}$ and $\mathrm{b}$. The specially designed $\mathrm{X}$-Y axes pulse motor stages, manufactured by Chuo Precision Industrial Co., Ltd (positioning accuracy $50 \mu \mathrm{m}$; unidirectional repeatability $\pm 5 \mu \mathrm{m}$ ), the charge-coupled device (CCD) camera, the light-emitting diode (LED) light source and the X-ray camera (Rad-icon Shad-o-Box 1024) with X-ray source device (Rigaku SLX-2000, $60 \mathrm{kV}$ and $250 \mathrm{~mA}$ ) were assembled to detect each crystal orientation within thin-section samples. Since all devices were installed in a cold laboratory at $-15^{\circ} \mathrm{C}$, a cold chamber or cryo-stage was not required. For ice-core studies, we prepared standard thin sections of $\sim 100 \mathrm{~mm} \times 100 \mathrm{~mm}$ with a thickness of $<0.5 \mathrm{~mm}$ for crystallographic analyses. Sections this large are necessary to observe a few hundred grains because of the large grain sizes, typically a few millimetres to a few centimetres in natural polar ice. Crystal orientations of $>200$ grains are required for sufficient fabric determination.

\section{Development of a semi-automated Laue X-ray diffraction method}

Using an earlier version of this device (Miyamoto and others, 2005), we had already succeeded in obtaining 
a

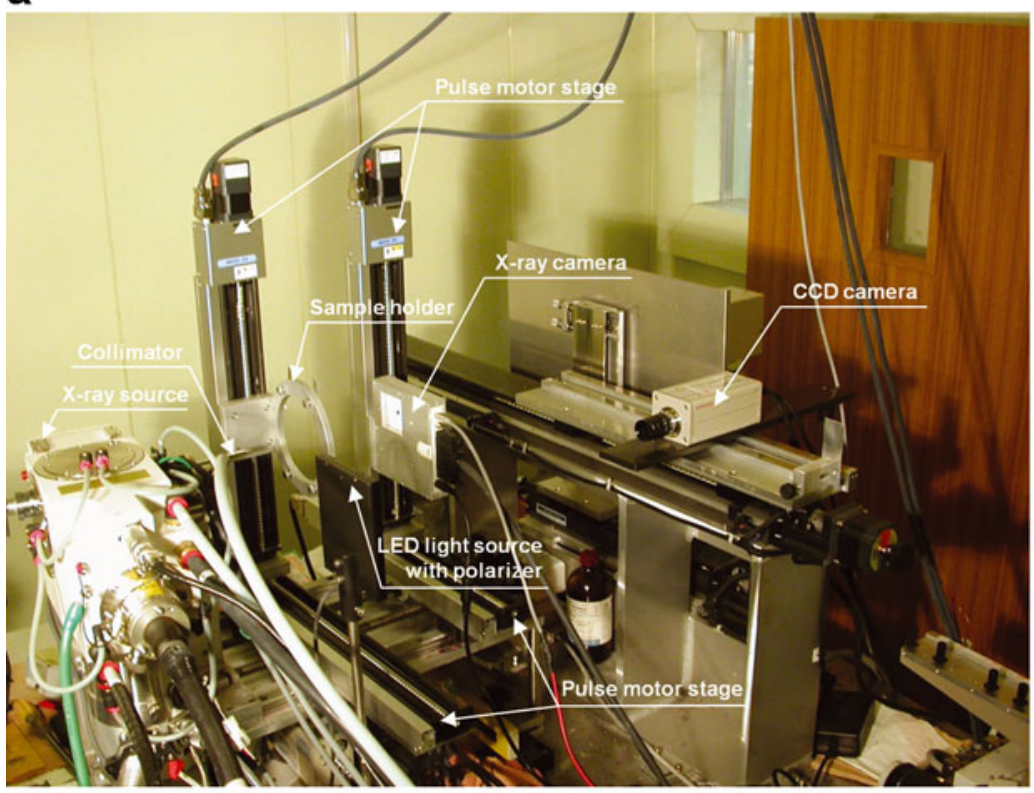

b

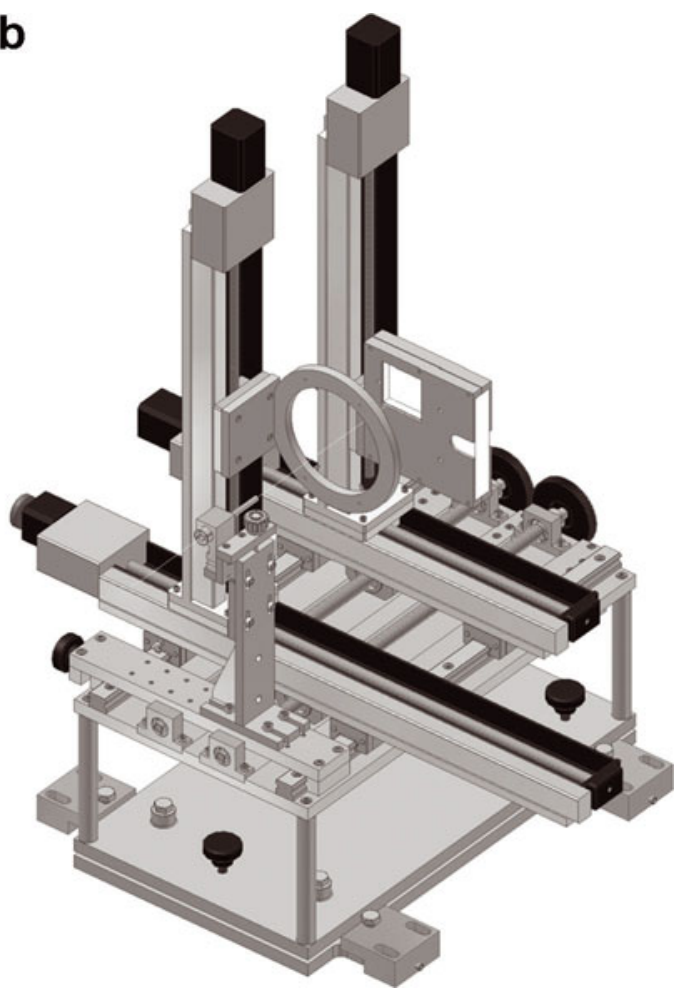

Fig. 1. (a) Photograph of entire experimental arrangement in cold laboratory. (b) Schematic of X-Y stages, collimator, sample holder and X-ray camera.

accurate $c$ - and a-axis orientation measurements, providing complete ice-core thin-section crystal orientation of fabrics. In our study, however, longer analysis times were required for a single grain, so it was not suitable for many measurements. In order to reduce measurement time and apply the method to microstructure studies, we aimed to automate the analysis of Laue X-ray diffraction, which is traditionally used only in single crystal analysis.

The Laue pattern digitizing and analysis software was developed in collaboration with Norm Co., Ltd, a Japanese software company that develops various X-ray analyses. However, this software is designed to analyse the orientation of single crystals and is unsuitable for the study of polycrystals. Thus, we 'customized' the software to the requirements of ice-core analysis. Specifically, the following changes were made so as to analyse many measurement points in a reasonable time:

1. The objective orientations ( $c$-axis and three a-axes) were inputted in advance.

2. After each individual analysis, the $c$-axis and three a-axes orientations were sent to a text file.

3. Many minor changes, such as the Laue pattern simulation algorithm for finding a matching pattern (the solution) and the procedure cycle (opening the Laue figure, digitizing Laue spots, finding a matching pattern, displaying the result and saving the result), were implemented to reduce analysis time. With the previous software we required a long calculation time and several operator interactions when proceeding to the next operation.

The present program version is 5.1.1.

The steps in our crystal-orientation analysis are as follows:
1. We prepare a thin section using an X-ray transparent object slide that consists of a $2 \mathrm{~mm}$ thick clear acrylic resin plate. The maximum size of the thin section is $\sim 100 \mathrm{~mm} \times 100 \mathrm{~mm}$, and the thickness is $<0.5 \mathrm{~mm}$ depending on grain size. The ice-sample thin section is covered with silicone oil and polyester film to avoid sublimation during measurement. The sample is inserted into the sample holder of the X-ray device (Fig. 2). This is the only step that had to be performed in a cold laboratory.

2. We decide upon a measurement position through the CCD camera with a polarizer using a stage controller. We recognize each grain on the monitor according to the

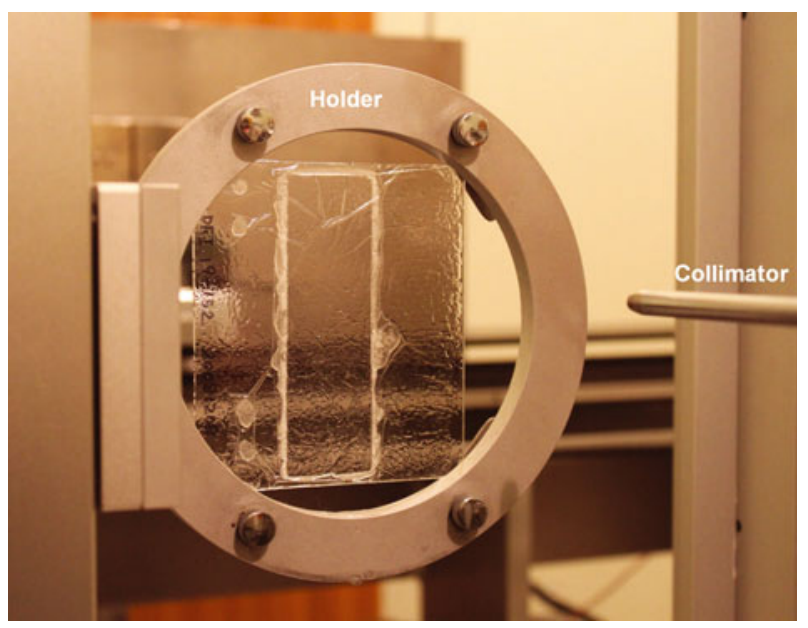

Fig. 2. Photograph of sample holder with ice core, thin-section sample. 


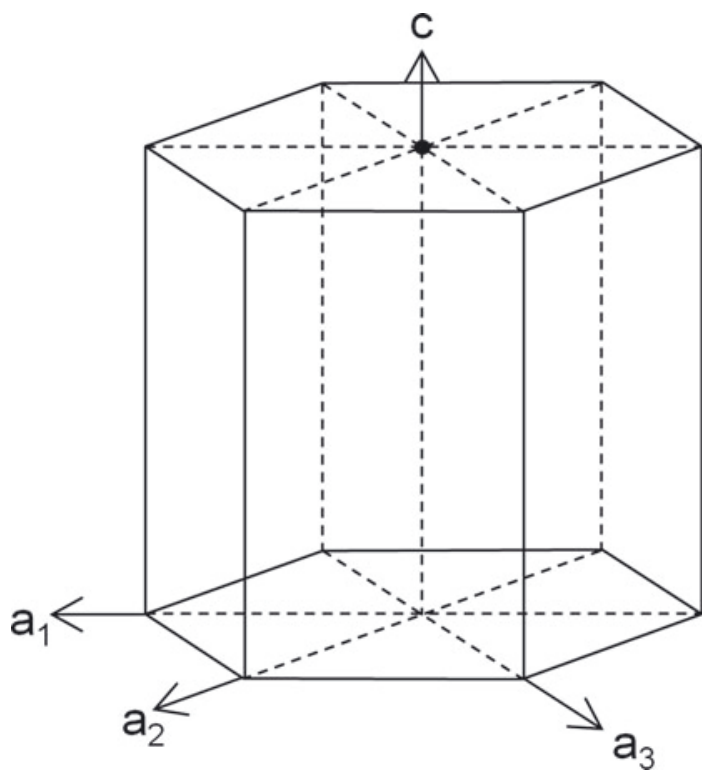

Fig. 3. Schematic diagram of measured four axes $\left(c, a_{1}, a_{2}\right.$ and $\left.a_{3}\right)$ of hexagonal ice crystal.

grey-value differences. We fix measurement points by operating the $X-Y$ stage using a joystick manipulator. The $X$-ray collimator axis and fixed point on the monitor are already linked. The measurement positions are saved as a series of X-Y coordinates in a text file. When we want to make equally spaced measurement points or grid measurement points for microstructure study or other purposes, we edit a test file that represents such coordinates or we move the $\mathrm{X}-\mathrm{Y}$ stage equidistant to the stage controller. The minimum detectable grain size is $\sim 0.5 \mathrm{~mm}$, which is larger than the collimator size; smaller grains were difficult to recognize through the CCD camera.

3. The actual Laue measurements, i.e. positioning on the measurement point, irradiation of X-ray and imaging of the Laue figure by the $\mathrm{X}$-ray camera, are fully automated in our system.

4. After obtaining all Laue figures, we prepare the Laue pattern digitizer and analysis program. The objective four orientations, (001) as $C$-axis and (210), (110) and (120) as a-axes (Fig. 3), are inputted to the software.

5. A few Laue spots from different crystal zones are digitized manually, and solution candidates for the Laue diagram are calculated by the software. If a candidate is provided, we confirm the simulated Laue pattern of the solution (Fig. 4) to reduce analysis error. The calculated orientations are sent to a result file.

The described improvements and modifications of the system make the X-ray analyser very suitable for ice-core studies. Using this semi-automated system, we were able to analyse $\sim 200$ measurement points every day.

\section{RESULTS AND DISCUSSIONS}

\section{Spatial resolution}

As previously mentioned, we need large thin sections due to the comparatively large grain size of natural polar ice-core

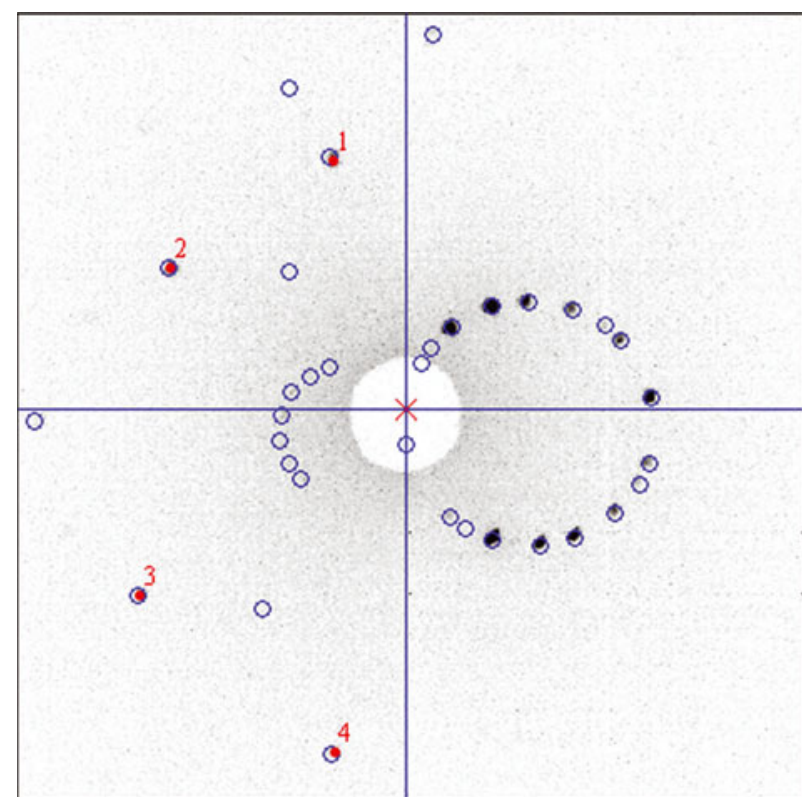

Fig. 4. Displayed Laue figure on Laue pattern digitization and analysis program. The black dots indicate original Laue pattern from $\mathrm{X}$-ray camera. The four numbered red dots show digitized points just on the acquired Laue spots. The open blue circles indicate simulated Laue pattern. The comparison of simulated and measured spots enables high accuracy and accelerated measurements.

samples, typically greater than a few millimetres. However, since grain substructure characterization is essential to understand the dislocation dynamics, the spatial resolution is important. The diameter of the X-ray beam we set up was $0.2 \mathrm{~mm}$, determined by the collimator size, which is suitable for adjusting a correlation between the $X$-ray power and the quality of the Laue spots figure - the sensitivity of the X-ray camera - in this setting. With the collimator size set to the smallest diameter of $0.1 \mathrm{~mm}$, the diffracted X-ray power was very low in order to obtain a satisfactory Laue figure. This beam size defined the minimum spatial resolution. The positioning accuracy of the $X-Y$ stage was one order smaller than this resolution.

For fabric determination, we chose a measuring point near the centre of each crystal and provided data as shown by Miyamoto and others (2005). Small crystal-orientation changes on subgrain boundaries or continuous lattice bending was observed when we moved the pulse motor stage in $>0.2 \mathrm{~mm}$ steps within an individual grain. Even with small crystal displacement, slight changes of spot position were detected in each Laue diagram. Such small orientation changes represent new and important microstructure information for ice-core study, especially those concerning distinct subgrain boundaries.

\section{Angular precision and accuracy}

Due to the grain boundary energies (Suzuki, 1970), subgrain misorientations are expected to be $<10^{\circ}$ as in metals (Humphreys and Hatherly, 2004) or even $<5^{\circ}$ as in most rock-forming minerals (Passchier and Trouw, 1996). Hence, when using Laue X-ray diffraction, the angular precision is of particular importance. The process of digitizing Laue spots is a primary factor for error generation because a slight deviation of digitizing position leads to low angle precision. For this reason, the precision was determined from repeated 

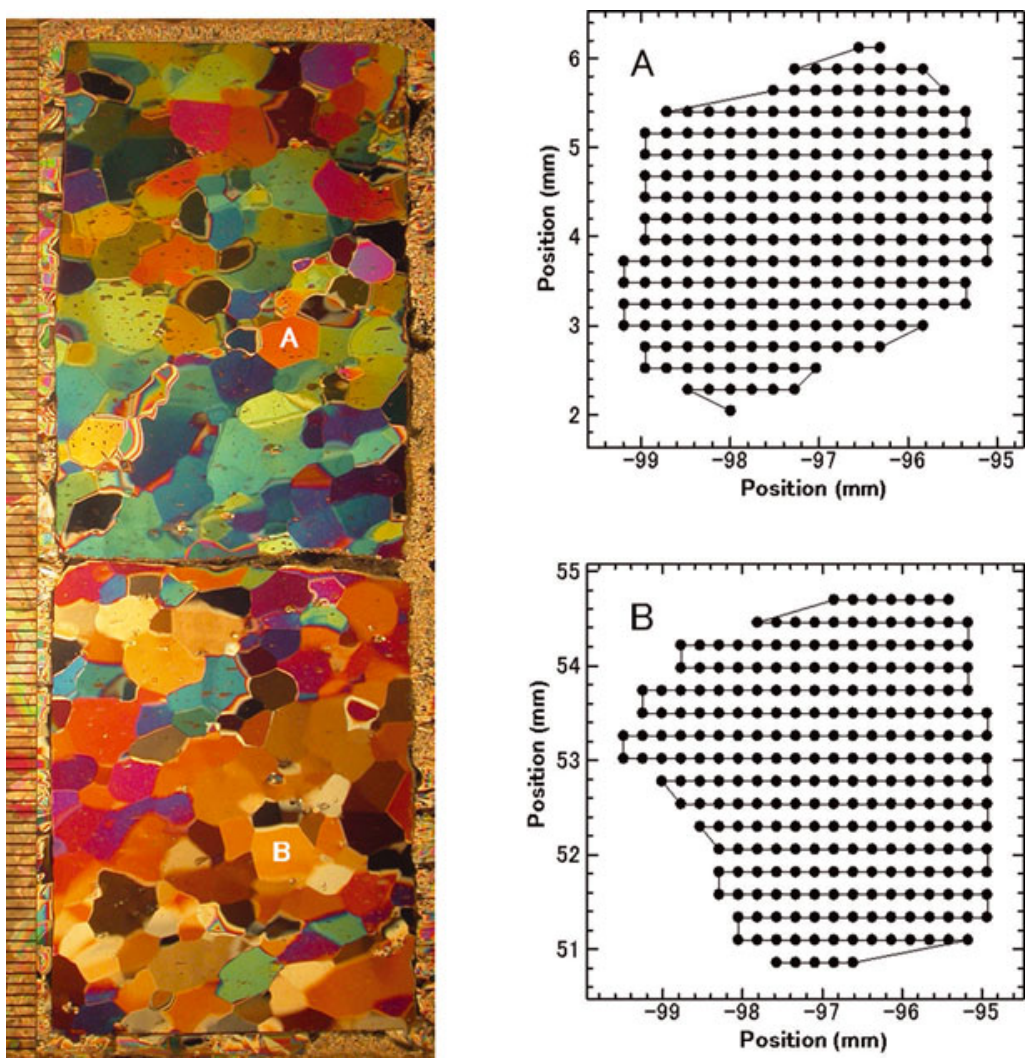

Fig. 5. Example of thin section prepared from the Greenland Icecore Project (GRIP) ice-core sample at $2702 \mathrm{~m}$ depth (left). This photograph was taken between crossed polarizers. The minimum scale on the left side shows $1 \mathrm{~mm}$. The black dots (right-hand graphs) show measurement points within grains $\mathrm{A}$ and $\mathrm{B}$.

analyses of the same Laue figure. The standard deviation of each orientation was $<0.5^{\circ}$. To estimate the accuracy of orientation determination, we compare it with the result of X-ray diffract meter measurement. For orientations determined by the Laue method, the desired ice-lattice plane orientations were searched using rocking curve measurements. This allowed us to seek the absolute orientation if the grain showed a perfect crystal without any disturbance such as polygonization or lattice bending. Both results showed good agreement, with some angle differences less than the standard deviation determined by the Laue measurements. The precision and accuracy with which an orientation can be absolutely determined is $\sim 0.5^{\circ}$ and is affected by the digitizing of Laue spots and the crystal quality. However, the relative orientations between neighbouring measurement points are the crucial parameter when detecting and characterizing subgrain boundaries. Pre-mapping of samples using sublimation etching by microstructure mapping (Kipfstuhl and others, 2006) gives a first impression of the crystal quality by revealing subgrain boundaries as grooves. Thus, this method enables the identification of undisturbed grains. Subsequent Laue X-ray diffraction measurements within these undisturbed grains and misorientation calculation of adjacent points reveal some noise below $\sim 0.5^{\circ}$. Possible continuous lattice bending, which does not evoke sublimation etch grooves in the undisturbed grains, can be ruled out by spatially referenced examination of misorientation data. Thus, the $0.5^{\circ}$ data noise can be regarded as the relative angular precision. In this study, we calculated the misorientation angle of the $c$ - and a-axes separately between neighbouring measurement points. For the a-axis measurements, we calculated the misorientation angle between each $a_{1}$ axis of neighbouring measurement points. The other two axes, $a_{2}$ and $a_{3}$, were also calculated in this way, but, since the ice crystal has six rotational symmetries about the $c$-axis, we had to find the a-axes combinations to minimize each of its misorientation angles.

\section{Subgrain structure measurement}

We adapted our Laue X-ray method to analyse subgrain structures within ice crystals. We performed measurements on a grid in individual ice crystals in a thin-section sample (Fig. 5). The numbers of measurement points in grains $\mathrm{A}$ and $B$, which have diameters of $\sim 4 \mathrm{~mm}$, are 230 and 257, respectively. When grains were near-perfect crystals, Laue spots of each measurement point appeared at the same position in the Laue diagram. On the other hand, when a grain had some subgrain structures, we observed spots out of position compared with adjacent points in each Laue figure. Figure 6 shows a result of multilayered, superposed Laue figures of all measurement positions in grains $A$ and $B$. The Laue spots of grain A exhibit the original shape of the X-ray beam, i.e. Laue spots appear at the same position in all Laue figures. There is a lack of crystal orientation changes within this grain. Only some noise below $\sim 0.5^{\circ}$ is observed (see above). On the other hand, the Laue spots in grain B do not retain the original shape of the $\mathrm{X}$-ray beam. The spot position in each Laue figure shifts slightly due to small changes in crystal orientation, indicating subgrain structures such as a subgrain boundary or continuous lattice bending.

Figure 7 shows an example of a misorientation angle across a discrete subgrain boundary in a Dome Fuji 

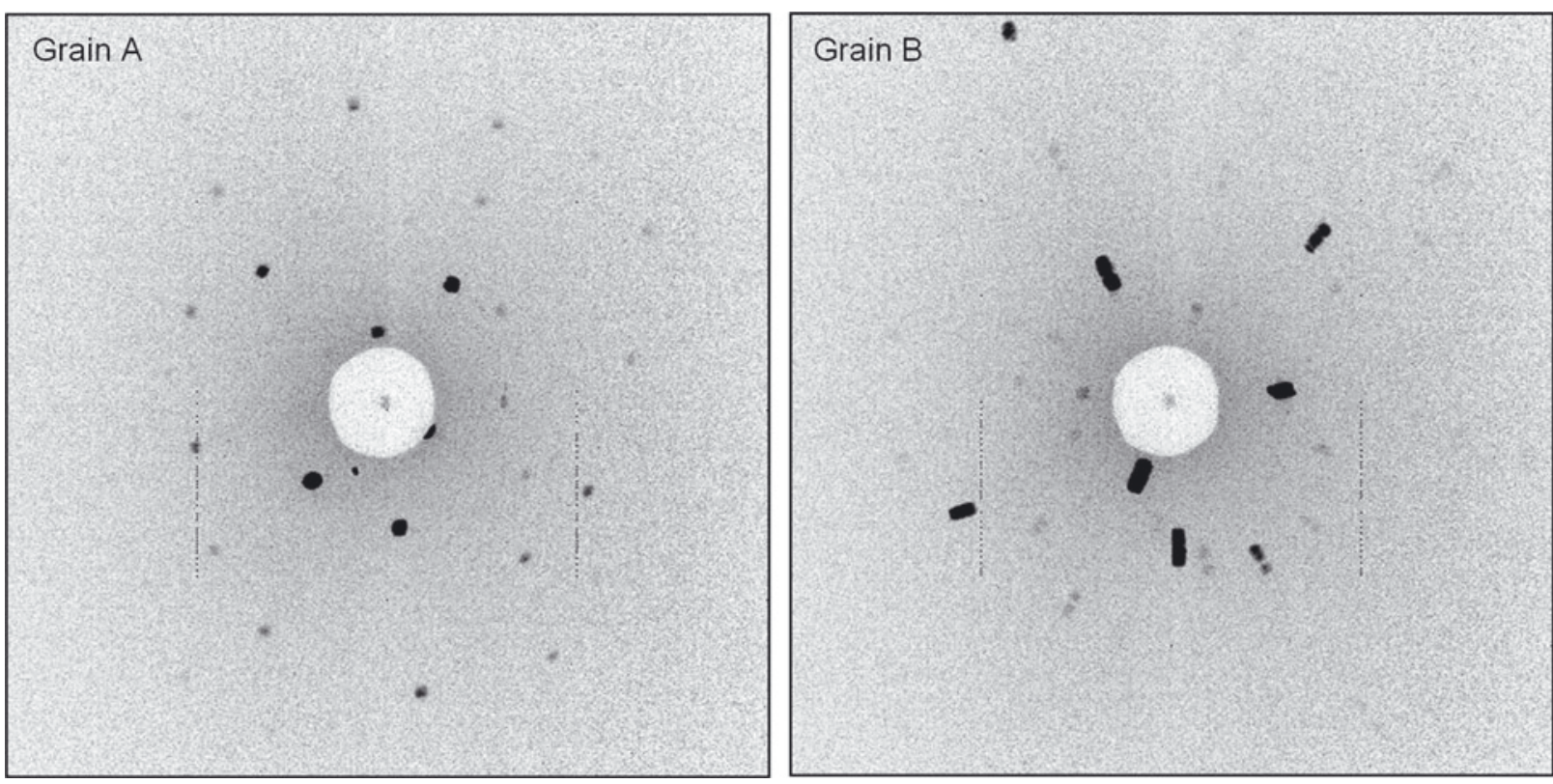

Fig. 6. Multilayered Laue figures from grains A and B. The Laue images of the 230 measurements for grain A and the 257 measurements for grain B are superposed. The stretching spots on Laue figure of grain B are evidence of Laue spots changing position with each measurement. In fact, if we observe all Laue figures of grain B as an animation movie, we readily understand the movement of the spots as the crystal lattice changes from point to point.

(Antarctica) ice-core sample, which was pre-localized using an optical microscope and microstructure mapping technique (Kipfstuhl and others, 2006). This method provides a qualitative possibility to distinguish between a distinct subgrain boundary and continuous lattice bending. We can observe subgrain boundaries as shallow sublimation grooves compared with deep, high-angle grain boundary grooves using the sublimation-etch method. The misorientation angle of the subgrain boundary in Figure 7 was determined from the analysis along a line crossing the subgrain boundary. The results indicate that the $c$-axis orientation hardly changes, whereas the a-axes show a misorientation angle. This crystal orientation relation across the subgrain boundary shows $\sim 3^{\circ}$ of rotation around the $c$-axis. This novel result for natural polar ice can be produced from the complete determination of several ice crystal orientation measurements in reasonable time by our semi-automated Laue X-ray diffraction method.

Further measurements show crystal orientation relations on subgrain boundaries with rotations of $\sim 2^{\circ}$ around one a-axis (Fig. 8). We emphasize that these are the first measurement results of the misorientation angle across subgrain boundaries in ice-core samples. They reveal the characteristics of the orientation relationship across a discrete subgrain boundary such as the previously mentioned misorientation relationship for rotation around the $c$-axis and one a-axis, and the orientation pattern on the subgrain boundaries can be classified. Each result shows an example of a twist boundary and a tilt boundary as the subgrain rotation mechanism. This microstructure could not be determined without the complete measurement of ice crystal orientation on the subgrain boundaries. Detailed analysis and novel statistics on subgrain boundary misorientations in natural Antarctic ice-core samples (EDML (EPICA Dronning Maud Land) ice core) enabled by this new Laue X-ray method, along with microstructure mapping, are described by Weikusat and others (2011).

\section{CONCLUSION}

Our new Laue X-ray diffraction method is customized for analysis of ice-core thin-section samples. It can measure full crystal orientations ( $c$-axis and a-axes) accurately. The important improvements obtained with our new method are:

1. Complete determination of ice-crystal orientation, including a-axis.

2. Highly accurate measurements compared with traditional methods.

3. Application to standard-sized $(100 \mathrm{~mm} \times 100 \mathrm{~mm})$ thinsection samples to produce sufficient statistical results and easy combination with standard methods such as microstructure mapping.

4. Spatial resolution of $\sim 0.2 \mathrm{~mm}$, which is less than the grain-size scale of natural polar ice.

5. Relative angular resolution of $\sim 0.5^{\circ}$, which is excellent for grain statistics and below the hypothetical transition between high-angle grain boundaries and subgrain boundaries (Suzuki, 1970), relevant for substructure studies.

6. Easy procedure. Each step, other than step 1, is completely operable outside the cold laboratory.

7. Numerous data points to measure physical properties of ice throughout the ice core, processed in a relatively short time through semi-automatic measurements.

The application of this method for grain statistics and subgrain studies will be a practical and powerful tool for crystallographic study of ice-core samples. The combination of our new method with microstructure mapping (Kipfstuhl and others, 2006) is an important improvement. It is difficult to observe subgrain boundaries between crossed polarizers due to the expected low misorientation angles of less than a 

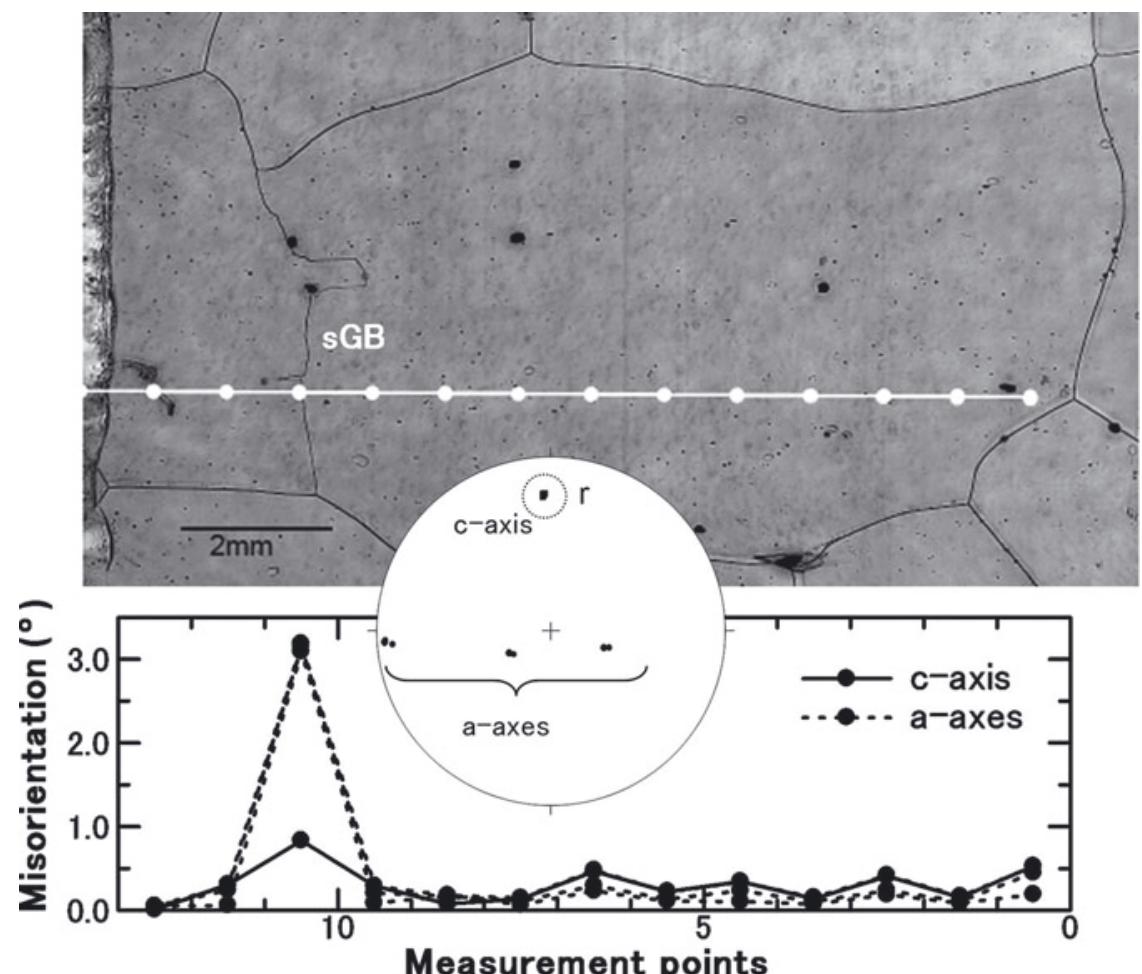

Fig. 7. Sample from the Dome Fuji ice core at $1975 \mathrm{~m}$ depth. The upper photo shows the grain with subgrain boundary, which was taken using the microstructure mapping technique (Kipfstuhl and others, 2006). The subgrain boundary (sGB) can be observed as the faint black line compared with the grain boundary. The white dots on the line indicate the measurement points. The lower graph shows the misorientation angle between each adjacent measurement point. All measured orientations are plotted on the stereo net. The orientation of the $c$-axis from each measurement point in the dotted open circle is almost unchanged, although the measurements are taken across the subgrain boundary. The symbol ' $r$ ' indicates the rotation axis associated with this subgrain boundary. This is an example of rotation around the $c$-axis on a subgrain structure.

few degrees on subgrain boundaries in ice, estimated by grain-boundary energy measurements (Suzuki, 1970). Our system will satisfy the demands of ice-core researchers such as Kipfstuhl and others (2006, 2009), Hamann and others
(2007) and Weikusat and others (2009). Our goal is to make additional improvements toward a fully automated X-ray diffraction analysing system that will further facilitate and accelerate microstructural measurements in ice.

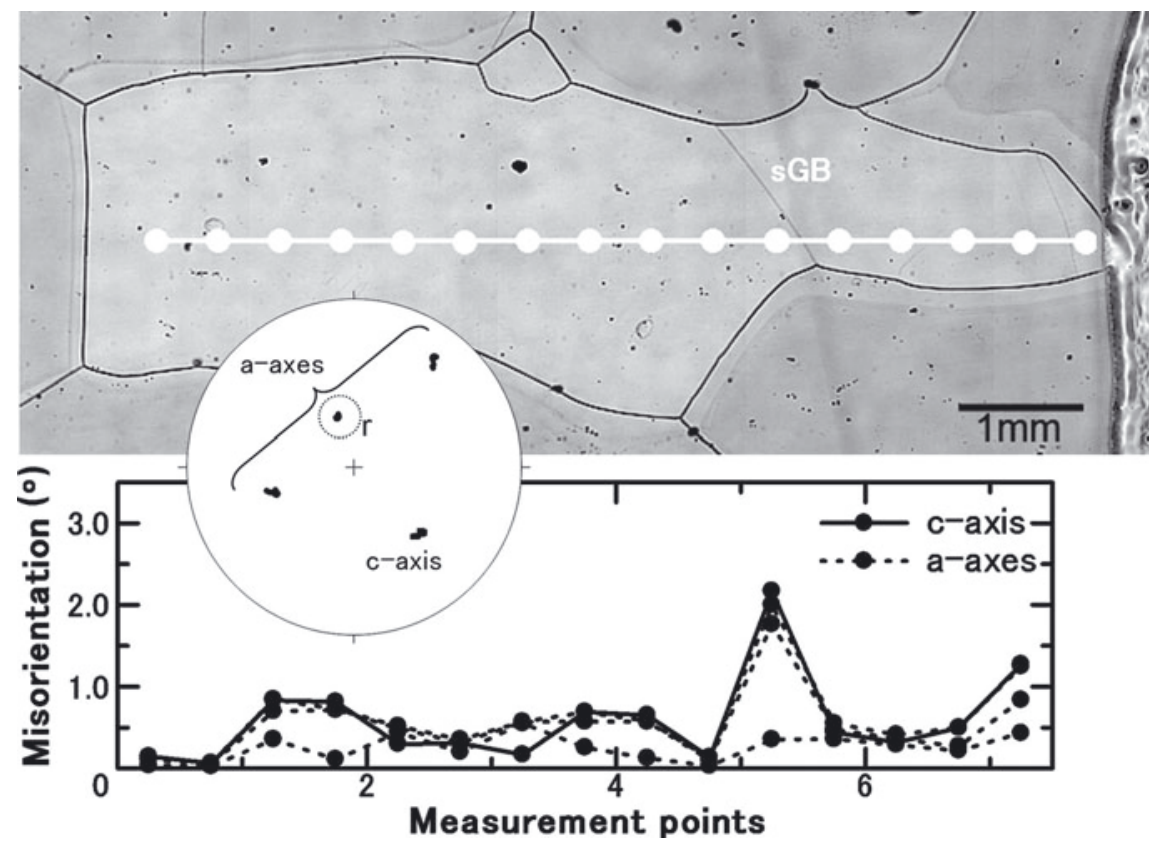

Fig. 8. Sample from the same section as Figure 7. The sample depth is also $1975 \mathrm{~m}$. This is an example of rotation around one a-axis on a subgrain structure. 


\section{ACKNOWLEDGEMENTS}

This work was supported by Creative Scientific Research (No. 14GS0202) from the Japanese Ministry of Education, Science, Sports and Culture, by Grant-in-Aid for Scientific Research (C) (No. 22540426) from Japan Society for the Promotion of Science and by the German Science Foundation (DGF HA 5675/1-1). We thank S. Nakatsubo and M. Ohi for technical advice and assistance, including the design of the X-ray device and the shutter control instrument. We thank S. Horikawa for support on the Laue imagegrabbing program and $\mathrm{A}$. Hori for support on X-ray diffraction measurement. We express appreciation to all members of the GRIP (Greenland) and Dome Fuji ice-core drilling projects. We thank the scientific editor, T. H. Jacka, and three anonymous reviewers for valuable comments and suggestions which improved the manuscript.

\section{REFERENCES}

Alley, R.B., A.J. Gow and D.A. Meese. 1995. Mapping c-axis fabrics to study physical processes in ice. J. Glaciol., 41(137), 197-203.

Azuma, N. and A. Higashi. 1985. Formation processes of ice fabric pattern in ice sheets. Ann. Glaciol., 6, 130-134.

Budd, W.F. and T.H. Jacka. 1989. A review of ice rheology for ice sheet modelling. Cold Reg. Sci. Technol., 16(2), 107-144.

Ewald, P.P., ed. 1962. Fifty years of x-ray diffraction. Chester, International Union of Crystallography.

Gow, A.J. and T. Williamson. 1976. Rheological implications of the internal structure and crystal fabrics of the West Antarctic ice sheet as revealed by deep core drilling at Byrd Station. CRREL Rep. 76-35.

Hamann, I., C. Weikusat, N. Azuma and S. Kipfstuhl. 2007. Evolution of ice crystal microstructure during creep experiments. J. Glaciol., 53(182), 479-489.

Herron, S.L. and C.C. Langway, Jr. 1982. A comparison of ice fabrics and textures at Camp Century, Greenland and Byrd Station, Antarctica. Ann. Glaciol., 3, 118-124.

Higuchi, K. 1958. The etching of ice crystals. Acta Metall., 6(10), 636-642.

Hull, D. and D.J. Bacon. 2001. Introductions to dislocations. Fourth edition. Oxford, etc., Butterworth Heinemann.

Humphreys, F.J. 2001. Review: grain and subgrain characterisation by electron backscatter diffraction. J. Mater. Sci., 36(16), 3833-3854.

Humphreys, F.J. and M. Hatherly. 2004. Recrystallization and related annealing phenomena. Second edition. Oxford, etc., Pergamon Press.

Iliescu, D., I. Baker and H. Chang. 2004. Determining the orientations of ice crystals using electron backscatter patterns. Microsc. Res. Tech., 63(4), 183-187.

Kamb, W.B. 1962. Refraction corrections for universal stage measurements. I. Uniaxial crystals. Am. Mineral., 47(3), 227-245.

Kipfstuhl, S. and 6 others. 2006. Microstructure mapping: a new method for imaging deformation-induced microstructural features of ice on the grain scale. J. Glaciol., 52(178), 398-406.
Kipfstuhl, S. and 8 others. 2009. Evidence of dynamic recrystallization in polar firn. J. Geophys. Res., 114(B5), B05204. (10.1029/ 2008JB005583.)

Langway, C.C., Jr. 1958. Ice fabrics and the universal stage. SIPRE Tech. Rep. 62.

Matsuda, M. 1979. Determination of a-axis orientations of polycrystalline ice. J. Glaciol., 22(86), 165-169.

Miyamoto, A., H. Shoji, A. Hori, T. Hondoh, H.B. Clausen and O. Watanabe. 2005. Ice fabric evolution process understood from anisotropic distribution of a-axis orientation on the GRIP (Greenland) ice core. Ann. Glaciol., 42, 47-52.

Obbard, R., I. Baker and K. Sieg. 2006. Using electron backscatter diffraction patterns to examine recrystallization in polar ice sheets. J. Glaciol., 52(179), 546-557.

Passchier, C.W. and R.A.J. Trouw. 1996. Microtectonics. Berlin, etc., Springer-Verlag.

Pennock, G.M. and M.R. Drury. 2005. Low-angle subgrain misorientations in deformed $\mathrm{NaCl}$. J. Microsc., 217(2), 130-137.

Piazolo, S., M. Montagnat and J.R. Blackford. 2008. Sub-structure characterization of experimentally and naturally deformed ice using cryo-EBSD. J. Microsc., 230(3), 509-519.

Prior, D.J., J. Wheeler, L. Peruzzo, R. Spiess and C. Storey. 2002. Some garnet microstructures: an illustration of the potential of orientation maps and misorientation analysis in microstructural studies. J. Struct. Geol., 24(6-7), 999-1011.

Randle, V. and O. Engler. 2000. Introduction to texture analysis: macrotexture, microtexture and orientation mapping. Amsterdam, Gordon and Breach.

Rigsby, G.P. 1951. Crystal fabric studies on Emmons Glacier, Mount Rainier, Washington. J. Geol., 59(6), 590-598.

Schulson, E.M. and P. Duval. 2009. Creep and fracture of ice. Cambridge, etc., Cambridge University Press.

Suzuki, S. 1970. Grain coarsening of microcrystals of ice (III). Low Temp. Sci., Ser. A 28, 47-61.

Wang, Y. and N. Azuma. 1999. A new automatic ice-fabric analyzer which uses image-analysis techniques. Ann. Glaciol., 29, 155-162.

Weertman, J. and J.R. Weertman. 1992. Elementary dislocation theory. Oxford, etc., Oxford University Press.

Weikusat, I., S. Kipfstuhl, S.H. Faria, N. Azuma and A. Miyamoto. 2009. Subgrain boundaries and related microstructural features in EDML (Antarctica) deep ice core. J. Glaciol., 55(191), 461-472.

Weikusat, I., A. Miyamoto, S.H. Faria, S. Kipfstuhl, N. Azuma and T. Hondoh. 2011. Subgrain boundaries in Antarctic ice quantified by Laue X-ray diffraction. J. Glaciol., 57(201), 111-120.

Weikusat, I., D.A.M. de Winter, G.M. Pennock, M. Hayles, C.T.W.M. Schneijdenberg and M.R. Drury. In press. Cryogenic EBSD on ice: preserving a stable surface in a low pressure SEM. J. Microsc.

Wilen, L.A., C.L. DiPrinzio, R.B. Alley and N. Azuma. 2003. Development, principles, and applications of automated ice fabric analyzers. Microsc. Res. Tech., 62(1), 2-18.

Wilson, C.J.L., D.S. Russell-Head, K. Kunze and G. Viola. 2007. The analysis of quartz c-axis fabrics using a modified optical microscope. J. Microsc., 227(1), 30-41. 